\title{
EKRANISASI UNSUR NARATIF DALAM FILM CAHAYA CINTA PESANTREN SUTRADARA RAYMOND HANDAYA
}

\author{
Muhammad Ali Mursid Alfathoni \\ Prodi Televisi dan Film \\ Fakultas Seni dan Desain Universitas Potensi Utama \\ Mhd.ali8mursid@gmail.com
}

\begin{abstract}
ABSTRAK
Penelitian ini tentang proses ekranisasi unsur naratif dalam film Cahaya Cinta Pesantren sutradara Raymond Handaya. Film Cahaya Cinta Pesantren diproduksi oleh Fullframe Pictures yang dirilis pada tahun 2017 yang disutradarai oleh Raymond Handaya dan memiliki durasi sekitar 2 jam 28 menit 37. Film Cahaya Cinta Pesantren diangkat dari sebuah novel dengan judul Cahaya Cinta Pesantren karya seorang penulis yang bernama Ira Madan. Dalam film Cahaya Cinta Pesantren terdapat proses penciutan, penambahan dan perubahan bervariasi. Untuk mengungkap hal tersebut, peneliti menggunakan pendekatan deskripsi kualitatif dan teori ekranisasi Bluestone. Proses ekranisasi yang terjadi dalam film Cahaya Cinta Pesantren meliputi ekranisasi pada alur cerita, tokoh dan penokohan. Proses ekranisasi yang dilakukan terhadap film Cahaya Cinta Pesantren bertujuan untuk mengurangi durasi dalam pembuatan film dan bertujuan untuk menambah efek dramatis dalam penyampaian alur cerita di dalam film Cahaya Cinta Pesantren. Film Cahaya Cinta Pesantren juga sangat mencerminkan arti sebuah perjuangan dan persahabatan serta belajar untuk mengikhlaskan sesuatu dan mencoba untuk bisa menerima keadaan. Film Cahaya Cinta Pesantren mencerminkan arti sebuah pengorbanan kedua orang tua agar anaknya bisa menjadi yang terbaik.
\end{abstract}

Kata kunci: Ekranisasi, Naratif, Film Cahaya Cinta Pesantren Raymond Handaya.

\begin{abstract}
This research is about the process of the narrative element ekranisasi in the film Cahaya Cinta Pesantren directed by Raymond Handaya. Film Cahaya Cinta Pesantren produced by Fullframe Pictures released in 2017 directed by Raymond Handaya and has a duration of about 2 hours 28 minutes 37. Film Cahaya Cinta Pesantren is based on a novel titled Cahaya Cinta Pesantren by a writer named Ira Madan. In the film Cahaya Cinta Pesantren there is a shrinking process, variations and changes. To reveal this, the researchers used the qualitative description approach and Bluestone's theory of ekranisasi. The process of ekranisasi that occurs in the film Cahaya Cinta Pesantren includes ekranisasi in the storyline, characters and characterizations. The process of ekranisasi carried out on the film Cahaya Cinta Pesantren aims to reduce the duration of filmmaking and aims to add dramatic effects in the delivery of the storyline in the film Cahaya Cinta Pesantren. Film Cahaya Cinta Pesantren also reflects the meaning of a struggle and friendship and learns to recite something and try to accept the situation. The film Cahaya Cinta Pesantren reflects the meaning of the sacrifice of both parents so that their children can be the best.
\end{abstract}

Keywords: Ekranisasi, Narrative, Film Cahaya Cinta Pesantren Raymond Handaya

\section{PENDAHULUAN}


Perkembangan teknologi informasi pada saat ini sangat membawa dampak yang positif terhadap perkembangan perfilman Indonesia. Hal tersebut, ditandai dengan banyaknya judul film yang beredar di tengah-tengah masyarakat. Film sebagai produk media audio visual yang memadukan unsur gambar maupun audio dalam proses komunikasi sehingga informasi yang ada di dalamnya bisa tersampaikan dengan baik kepada penikmat film. Film merupakan bentuk karya seni yang dihasilkan dari serangkain gambar yang memiliki unsur sinematik maupun dramatik yang dihasilkan melalui teknik sinematografi sehingga membuat film menjadi media yang asyik untuk dinikmati. Pada masa sekarang ini maraknya produksi film di Indonesia tidak lepas dari sumber cerita yang dituturkan ke dalam nya. Sumber cerita tersebut dapat berasal dari berbagai sumber salah satunya novel. Nurgiyantoro (2010:4) menyatakan bahwa novel adalah sebuah karya fiksi yang menawarkan sebuah dunia yang berisi model kehidupan yang di idealkan, dunia imajinatif yang dibangun melalui berbagai unsur intrinsiknya seperti peristiwa, plot, tokoh dan penokohan, latar, dan sudut pandang yang kesemuanya bersifat imajinatif. Dapat dikatakan bahwa novel merupakan buah pikiran yang dihasilkan oleh seorang pengarang yang memuat unsur konflik, ruang dan waktu dan memiliki aspek dramatis dalam penulisannya.

Film Cahaya Cinta Pesantren merupakan film yang diadaptasi dari sebuah novel karya Ira Madan dengan judul Cahaya Cinta Pesantren. Fenomena pengadaptasian novel ke film bukanlah fenomena baru di dunia perfilman. Menurut Garin Nugroho (1995) terdapat 85\% film pemenang Oscar merupakan hasil adaptasi dari karya sastra seperti novel. Sementara itu, $83 \%$ mini seri program televisi juga dihasilkan dari proses adaptasi dari novel. Bahkan, 70\% film yang meraih Emmy Award juga dihasilkan dari proses adaptasi dari novel. Film-film yang menghiasi layar lebar Indonesia yang diadaptasi dari novel seperti film Ketika Cinta Bertasbih yang diangkat dari novel karya Habiburrahman El Shirazy dengan judul yang sama dan disutradarai oleh Chaerul Umam. Film Assalamu'alaikum Calon imam sutradara Findo Purwo HW yang diangkat dari Novel Assalamu'alaikum Calon Imam karya seorang penulis yang bernama Ima Madaniah yang di produksi pada tahun 2016 oleh Prized Production dan Vinski Production. Selanjutnya, film Dilan yang diproduksi oleh Falcon Pictures dan Maxima Pictures pada tahun 2017 dan di sutradarai oleh Fajar Bustomi. Film Dilan diangkat dari sebuah novel dengan judul Dilan karya Pidi Baiq.

Proses adaptasi karya sastra seperti novel ke film lebih dikenal dengan istilah ekranisasi. Ekranisasi merupakan proses pemindahan dari sebuah novel menjadi sebuah film yang memadukan unsur audio visual. Menurut Bluestone dalam bukunya yang berjudul Novel Into Film (1996) bahwa ekranisasi dapat berupa proses pemindahan ataupun perubahan dari novel menjadi film. Teori ekranisasi Bluestone akan digunakan oleh peneliti untuk menganalisis proses adaptasi yang terjadi dalam film Cahaya Cinta Pesantren sutradara Raymond Handaya. Proses ekranisasi dari sebuah karya sastra seperti film sering terjadi permasalahan yang diakibatkan film yang dihasilkan tidak sesuai dengan novel aslinya. Namun, tidak dapat dipungkiri bahwa karya adapatasi tentu mengalami perubahan apalagi novel yang berbentuk media tulis linguistik menjadi sebuah film yang berbentuk media audio visual. Proses pengadaptasian tentu adanya proses perubahan, penambahan maupun penyesuaian yang bertujuan untuk menambah efek dramatis pada alur cerita dalam film yang di produksi.

Serangkaian perubahan yang terjadi dalam film yang diangkat dari novel merupakan proses imajinasi kreatif. Seorang sutradara melakukan proses penambahan, pengurangan, maupun perubahan-perubahan yang mengandung unsur dramatik dalam alur cerita film. Untuk mendukung dalam mendeskripsikan unsur naratif dalam film Cahaya Cinta Pesantren peneliti menggunakan pendekatan deskriptif dengan metode kualitatif. Dengan demikian, proses ekranisasi unsur naratif yang terdapat dalam film Cahaya Cinta Pesantren dapat diuraikan berdasarkan cerita, plot, karakter, maupun tempat dan waktu. 


\section{II.STUDI LITERATUR}

Yang menjadi rujukan penelitian ini adalah hasil penelitian Bertha Galuh Andini tahun 2016 yang diterbitkan dalam jurnal Capture Institut Seni Indonesia Surakarta yang berjudul "Ekranisasi Unsur Naratif Dalam Film Life Of Pi" mengalami serangkaian perubahan setelah dilakukan proses visualisasi ke media film. Proses perubahan tersebut terjadi pada unsur naratif pada bagian cerita, plot, tokoh dan penokohan. Proses perubahan dalam film Life Of Pi mencangkup aspek penciutan, penambahan dan perubahan bervariasi. Dalam film Life Of Pi terdapat 4 sekuen. Akan tetapi, sutradara hanya melakukan perubahan pada tujuh sekuen dalam film Life Of Pi. Bertha Galuh Andini menggunakan teori ekranisasi Bluestone dalam mendeskripsi ekranisasi unsur naratif dalam Film Life Of Pi dengan memadukan pendekatan riset metode kualitatif. Bertha Galuh Andini menarik kesimpulan bahwa dalam film Life Of Pi sangat banyak terjadi perubahan dari segi unsur naratif.

Rujukan peneliti selanjutnya adalah hasil penelitian Selly Emala 2017 yang berbentuk skripsi dengan judul "Analisis Naratif Ekranisasi Novel "Supernova: Ksatria, Putri Dan Bintang Jatuh" ke Dalam Bentuk Film”. Selly Emala menggunakan metode kualitatif dan teori ekranisasi untuk menganalisis unsur naratif antara novel dengan film Supernova: Ksatria, Putri, dan Bintang Jatuh. Hasil analisis yang dilakukan oleh Selly Emala menemukan beberapa titik perbedaan bagi dari segi story, plot, karakter, ruang dan waktu serta dalam struktur dramatik. Supernova: Ksatria, Putri, dan Bintang Jatuh adalah novel best seller karya seorang penulis Dee Lestari yang diadaptasikan menjadi sebuah film. Namun, hasil adaptasi dari novel tersebut ke media film tidak terlalu diminati oleh penonton. Oleh karena itu, Selly Emala melakukan analisis ekranisasi antara novel dan film serta membedah setiap unsur-unsur naratif yang terdapat pada novel maupun film serta membandingkan hasil keduanya.

\section{PEMBAHASAN}

Film Cahaya Cinta Pesantren adalah sebuah film yang diproduksi oleh Fullframe Pictures yang dirilis pada tahun 2017 yang disutradarai oleh Raymond Handaya. Film Cahaya Cinta Pesantren menceritakan seorang anak bungsu dari tiga orang bersaudara. Anak tersebut bernama Marshila Silalahi anak seorang nelayan yang tinggal di daerah Danau Toba. Marshila merupakan anak kesayangan bapaknya dan memiliki ide yang cemerlang serta penuh ambisi untuk meraih cita-cita yang menjadi impiannya. Marshila memiliki citacita agar bisa bersekolah di SMA favorite yang berada di Kota Medan. Akan tetapi, ibunya tidak menyetujui keinginan Marshila bersekolah di SMA. Ibu Marshila lebih setuju jika Marshila masuk di sebuah pondok pesantren. Mengetahui hal demikian, Marshila mengiba kepada bapaknya agar dia tetap bisa bersekolah di SMA yang menjadi impiannya. Marshila merasa sangat kecewa sama bapaknya atas keputusannya mendukung niat mamanya agar Marshila tetap dimasukkan ke pesantren.

Kehidupan pondok pesantren yang sangat disiplin membuat Marshila sangat sulit beradaptasi dengan lingkungan pesantren. Ditengah padatnya kegiatan yang ada di pondok pesantren membuat Marshila meras bosan dan tidak betah. Namun, Marshila tetap bertahan dan memiliki impian menjadi seorang penulis novel yang terkenal dan bisa membanggakan kedua orang tuanya. Selama tinggal di pondok pesantren Marshila berteman dengan teman satu asramanya. Dalam pertemanan mereka Marshila menemukan arti dari sebuah persahabatan yang sebenarnya. Di dalam persahabatan mereka mengenal adanya "belanga air mata' yang berfungsi untuk menyimpan air mata kesedihan maupun kebahagian. Persahabatan yang terjalin antara Marshila dan teman-temannya senantiasa di isi dengan hal- 
hal yang membuat ketawa sehingga membuat mereka merasa bahagia ditengah aturan pesantren yang sangat disiplin. Selama di pesantren Marshila mendapat banyak hal yang menjadi pelajaran dalam kehidupannya dalam menemukan jati diri seorang remaja.

\section{III.1. Tahap Permulaan Pada Film Cahaya Cinta Pesantren}

Tahap permulaan pada film Cahaya Cinta Pesantren berdurasi kurang lebih sekitar 1 jam 01 menit 19 detik. Film Cahaya Cinta Pesantren berdurasi sekitar 2 jam 28 menit 37 detik. Akan tetapi, di dalam novel Cahaya Cinta Pesantren tahap permulaan kurang lebih ada sekitar 45 halaman dari jumlah keseluruhan novel. Dalam tahapan permulaan yang terdapat di dalam film maupun novel semua karakter pemeran yang ada di dalam novel diperkenalkan keseluruhan. Dalam film Cahaya Cinta Pesantren para pemerannya terdiri dari Yuki kato sebagai Marshila Silalahi, Febby Rastanty sebagai Manda, Vebby Palwinta sebagai Icut, Sivia Azizah sebagai Asiyah, Rizky Febian sebagai Abu, Elma Theana sebagai Mamak Shila, Tabah Penemuan sebagai Ayah Shila, Zee Zee Shahab sebagai Ustadzah Jannah, Fachri Muhammad sebagai Rifqy, Wirda Mansur sebagai Avira. Marshila Silalahi berperan sebagai tokoh utama di dalam film Cahaya Cinta Pesantren. Dalam tahapan permulaan film Cahaya Cinta Pesantren terdapat beberapa deskripsi ekranisasi sebagai berikut:

\section{a. Alur Cerita}

Dalam film Cahaya Cinta Pesantren diawali dengan memvisualisasikan keindahan danau toba yang terdapat di daerah Toba Samosir. Keindahan air danau terlihat kebiruan-biruan. Adapun capture gambar danau toba seperti berikut ini:

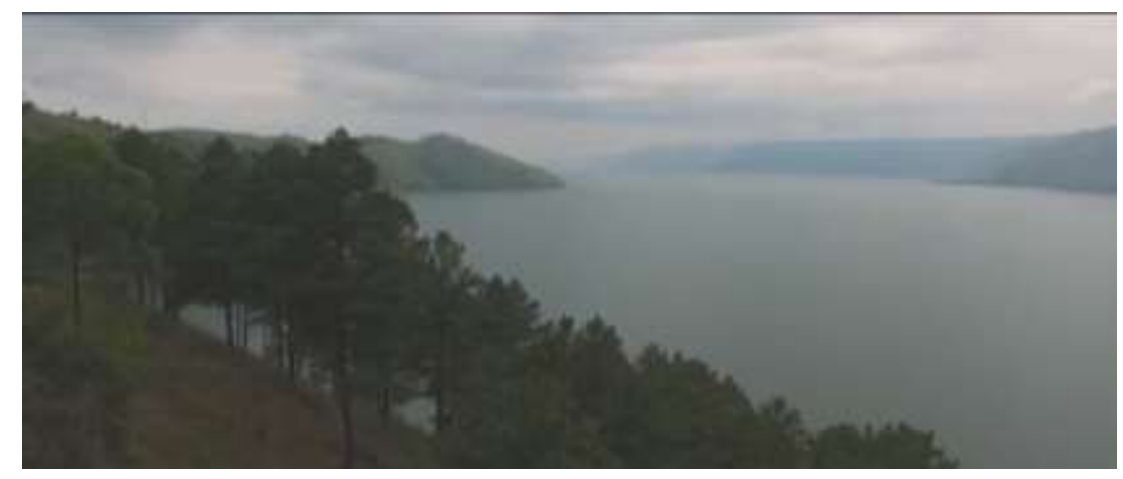

Gambar 1. Keindahan Danau Toba (sumber: Capture film Cahaya Cinta Pesantren. 2016)

Proses visualisasi berlanjut kepada memperkenalkan pemeran utama yang menceritakan siapa dirinya. Marshila Silalahi merupakan anak bungsu dari tiga bersaudara dan perempuan satu-satunya. Proses visualisasi berkelanjutan kesebuah rumah panggung khas orang Batak. Di dalam rumah tersebut terdapat seorang ibu yang sedang menggoreng ikan mas dan disampingnya ada seorang gadis kecil yang sedang melamun sambil memotong bawang. Ibu yang sedang memasak tersebut merupakan ibunya Marshila. Ibu Marshila menasehati Marshila supaya bisa memasak bukan bermain dengan laki-laki. Ketika ibunya lengah Marshila keluar rumah dan pergi bermain dengan teman-temannya. Keindahan pinggiran danau toba kembali di visualisasi untuk mendukung dramatik dari cerita dalam film Cahaya Cinta Pesantren. Pada tahapan alur cerita selanjutnya menceritakan Marshila senantiasa mengikuti bapaknya keperpustakaan. Marshila ikut dengan bapaknya bukan untuk membaca buku. 
Akan tetapi, Marshila datang ke perpustakaan hanya mengambil jumlah buku yang banyak dan menumpukkannya. Melihat kelakukan Marshila membuat bapak berusaha meminta maaf ke penjaga perpustakaan atas perlakuan yang dibuat oleh Marshila. Bapak Marshila merupakan sosok yang senantiasa menyelesaikan masalah Marshila dan selalu ada solusi bukan dengan amarah.

Cerita terus belanjut, Marshila tanpa menghiraukan ibunya pergi main hujan. Akan tetapi, berbeda dengan bapaknya yang membiarkan Marshila berbuat apa yang dia mau. Keseharian Marshila selalu dekat dengan bapaknya. Marshila tidak malu ikut bapaknya pergi menjala ikan dan menjualnya ke pasar. Setalah selesai menjual ikan di pasar pinggiran danau toba dan melaksanakn shalat. Marshila mendapat hadiah yang special dari bapaknya. Hadiah tersebut berupa sebuah novel. Marshila sangat bahagia atas hadiah yang diberikan bapaknya. Bapaknya selalu mengerti apa yang diimpikan oleh Marshila. Prose visualisasi berlanjut kepada memvisualisasi sebuah dinding rumah yang terpajang sebuah bingkai photo dengan balutan sebuah ulos berwarna merah. Walaupun Marshila memiliki watak yang keras dan susah diatur namun Marshila memiliki semangat belajar yang kuat serta tergolong anak yang cerdas. Namun, nasib berkata lain Marshila harus menerima kenyataan bahwa dia tidak lulus untuk masuk ke sekolah favorit yang dia impikan. Impian Marshila harus pupus karena kedua orang tuanya sepakat untuk memasukkan Marshila ke Pesantren. Ketika berada dilingkungan barunya Marshila berjumpa dengan teman-teman barunya dan berada di rayon khadijah 1. Ketika baru masuk ke pesantren tingkah laku Marshila tidak pernah berubah dan selalu bertindak semaunya.

b. Alur cerita dalam novel Cahaya Cinta Pesantren

Dalam novel Cahaya Cinta Pesantren menceritakan bahwa bulan ramadhan berakhir. pada saat bulan ramadhan bazar merupakan tempat favorit bagi warga kota Medan termasuk Marshila. Disekitar tempat bazar terdapat masjid kebanggan masyarakat koat Medan yaitu masjid al-mashundsan istana Maimun. Marshila sering dibawa ayahnay pergi ke perpustakaan disaat memiliki waktu kosong. Marshila ikut dengan ayahnya bukan untuk membca buku tetapi berjalan disetiap rak dan mengambil buku mana yang ia sukai dan menumpukkannya diatas meja. Akibat perbuatannya Marshila di tegur oleh petugas perpustakaan. Namun, ayahnya selalu ada solusi ketika dia terkena masalah. Marshila merupakan pelanggan rujak Wak Pungiyem sejak kecil. Wak Pungiyem senantiasa menceritakan kenakalan Marshila pada waktu kecil. Cerita selanjutnya yang terdapat di dalam novel merupakan cerita ketika Marshila di daftarkn ibunya ke sebuah pesantren. Keputusan ibu Marshila memasukkannya ke pesantren membuat dirinya dilanda kesedihan. Hati Marshila dipenuhi keluh kesah. Ayahnya tidak henti-henti memberikan nasihat kepadanta termasuk kakaknya. Rasa kesal Marshila semakin menjadi ketika dia bangun tengah malam untuk makan karena seharian menggurung diri dalam kamar. Marshila sangat sedih ketika sepotong lauk tidak ada diatas meja makan. Ayahnya mengetahui Marshila makan secara diam-diam menawarkan ayam goring. Namun, Marshila sangat acuh karena dilanda kesedihan. Marshila mencoba menyakinkan dirinya dan harus bisa membuat hati kedua orang tuanya senang seperti ketiga kakaknya.

Ketika di pesantren Masrhila tinggal di Rayon tiga pesantren Al-Amanah. Di tempat barunya Marshila menemukan teman-teman baru. Rasa kesedihan Marshila sedikit demi sedikit terobati dengan kehadiran teman-teman barunya. Hari demi hari dilalui oleh Marshila dengan teman-temannya di pondok pesantren. Tingkah mereka lain dari pada yang lain. Mereka memiliki cara tersendiri dalam menyelesaikan masalah yang mereka miliki. Di 
pondok pesantren mereka belajar public speaking yang berguna untuk melatih mental dan kemapuan setiap santri berbicara di depan khalayak ramai. Pada suatu hari ada pertandingan Persia Cup di pondok pesantren. Disana ada Abu bakar sosok santri putra yang selalu mengirim salam kepada Marshila Silalahi. Ditengah ejekan teman-temannya Marshila melihat sosok yang memiliki senyuman yang sempurna yang bergabung dalam Persia ( Persatuan Silat Al-Amanah).

\section{c. Ekranisasi cerita dalam Film Cahaya Cinta Pesantren pada tahap permulaan}

Pada tahapan permulaan dalam film Cahaya Cinta Pesantren mengalami proses penciutan pada cerita. Dalam film diawali dengan visualisasi keindahan danau toba dan kehidupan disekitarnya dan masa kecil Marshila. Akan tepai, di dalam novel diawali dengan mencerita berakhirnya bulan ramdhan dan medan fair di kota Medan, serta menceritakan masjid raya dan istana maimun. Di dalam film tidak ada adegan yang menceritakan Mashila membeli rujak Wak Pungiyem. Akan tetapi, Marshila memetik manga yang ada di pondok Pesantren. Dalam film Marshila dimasukkan ke dalam pondok pesantren dan tinggal di Rayon khadijah 1. Tetapi, di dalam novel Marshila masuk ke dalam pondok pesantren AlAmanah dan tingal di Rayon 3. Dalam film diceritakan bahwa Marshila memiliki dua orang kakak laki-laki dan di novel Marshila memiliki tiga orang kakak laki-laki. Di dalam film tidak diceritakan secara detail keberadaaan kakak Marshila dan di novel ketiga kak Marshila di ceritakan secara sangat detail. Dalam film awal mula Marshila masuk ke pesantren karena tidak lulus masuk SMA negeri dan berkeinginan masuk SMA Swasta tetpai tidak diizinkan oleh ibunya karena tidak mampu. Dan di dalam novel hal tersebut tidak diceritakan. Adapun adegan Marshila diantar oleh ibunya ke pesantren seperti terlihat pada gambar berikut ini:

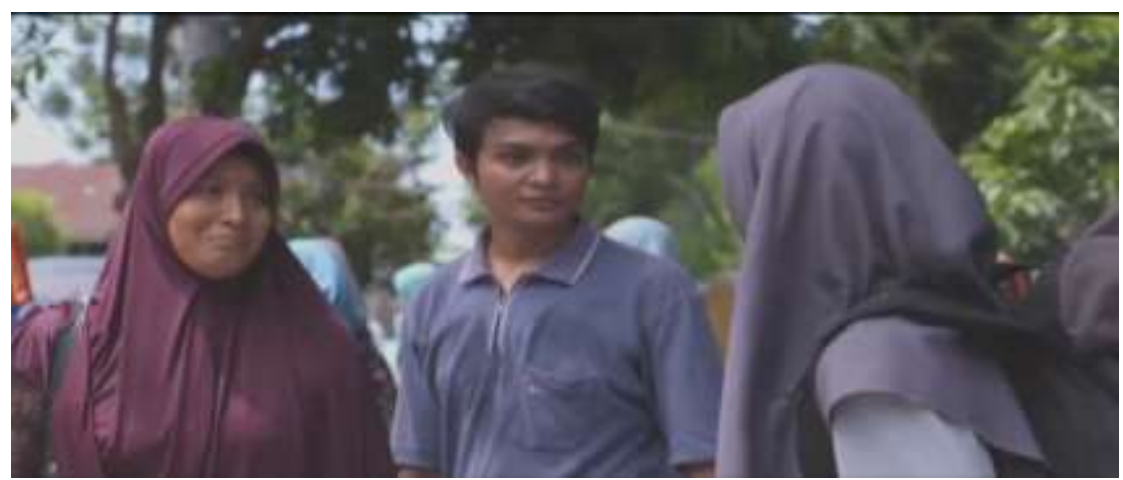

Gambar 2. Marshila diantar ke pesantren (sumber: Capture film Cahaya Cinta Pesantren. 2016)

Dalam film tidak diceritakan tentang sosok bunda Icut yang senantiasa berbelanja di Kota Medan dan datang ke pesantren untuk menjeguk anaknya. Tetapi dalam novel diceritakan. Dalam film diceritakan bahwa Marshila dan manda permisi keluar pondok untuk membeli obat ke apotik untuk Manda. Mereka keluar pondok pesantren untuk mencari udara segar dan mereka mendatangi mall terbesar di kota Medan membeli peralatan sabun, bedak pakaian dan lain-lain. Ketika berada diluar pondok membuat Marshila tidak mau pulang sebelum mencicipi mie aceh di Titi Bobrok. Dalam film keterlambatan Marshila dan Manda balik ke Pesantren karena mereka kemalingan dan mereka harus berjalan kaki dari Ringroad menuju pondok pesantren. Agar terbebas dari hukuman Marshila memercikkan air moneral ke baju mereka dan berlari ditempat agar terlihat macet. Dalam novel keterlambatan mereka disebabkan karena angkot yang mereka tumpangi terjebak macet. Mereka terbebas dari hukuman dengan menceritakan perihal macet kepada pengawas dengan sejujurnya. 
Setelah mereka di nasehati petugas keamanan Pesantren mereka disuruh agar segera kembali ke Rayon.

d. Ekranisasi Tokoh dan Penokohan dalam Film Cahaya Cinta Pesantren pada tahap permulaan

Dalam film Cahaya Cinta Pesantren terjadi proses penciutan dengan tidak menghadirkan tokoh Wak Pungiyem seorang penjual rujak yang sangat disukai oleh Marshila. Proses penciutan juga terjadi terhadap tokoh yang menceritakan ketiga kakak Marshila. Dalam film hanya diceritakan bahwa Marshila memiliki dua orang kakak dan divisualisasikan hanya 1. Adapun adegan yang memvisualisasikan kakak Marshila seperti terlihat pada capture film Cahaya Cinta Pesantren berikut ini:

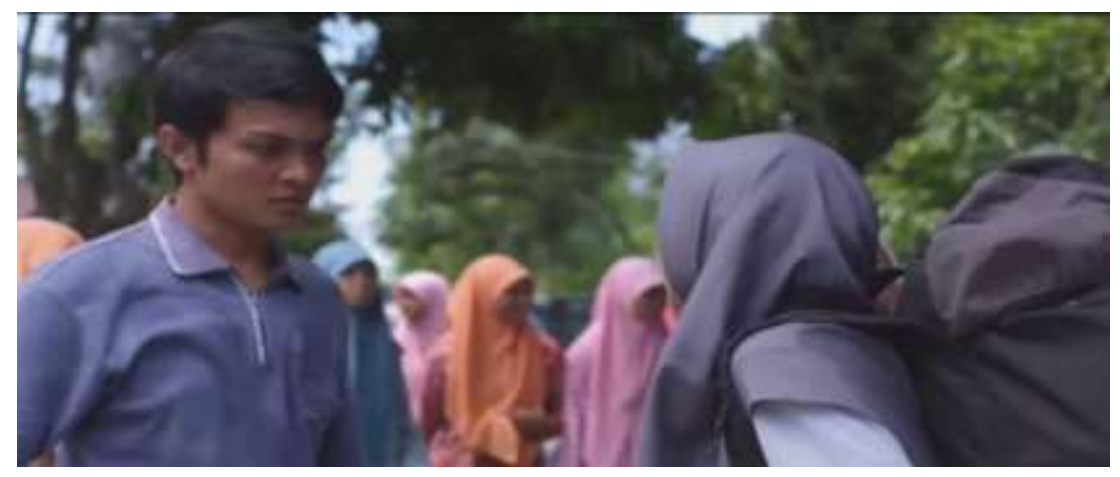

Gambar 3. Visualisasi Kakak Marshila (sumber: Capture film Cahaya Cinta Pesantren. 2016)

Proses penciutan juga dilakukan dengan tidak memvisualisasikan sosok bunda Icut yang senantiasa dating menjeguknya ke pondok Pesantren. Proses penciutan yang dilakukan terhadap film yang dihasilkan dari proses ekranisasi dari sebuah karya sastra dilakukan untuk menyesuaikan durasi waktu dan untuk mendapat efek dramatis disetiap alur cerita yang diperankan oleh parah tokoh. Proses penciutan juga terjadi dengan tidak memvisualisasikan penjual mie aceh yang terkenal enak yang diberada di Titi Bobrok. Dalam film Cahaya Cinta Pesantren juga terjadi proses penambahan tukang becak dan pencopet ketika Marshila dan Manda permisi keluar pondok. Alasan mereka berdua keluarga pondok untuk pergi ke apotik membeli obat asma Manda. Proses penciutan juga dilakukan dengan tidak menampilkan Mall terbesar yang mereka kunjungi pada saat mereka mendapat izin keluar pondok. Akan tetapi terjadi proses penambahan dengan menampilakan pasar tradiosional yang menjadi daya tarik tersendiri dalam film Cahaya Cinta Pesantren. Adapun adegan mereka naik becak terlihat pada capture film Cahaya Cinta Pesantren Berikut ini:

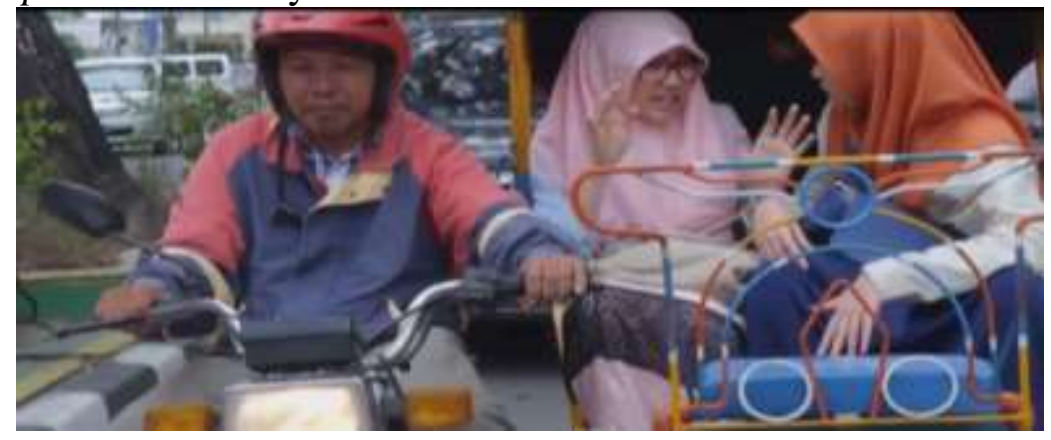

Gambar 4. Visualisasi Kakak Marshila (sumber: Capture film Cahaya Cinta Pesantren. 2016) 
Penciutan juga dilakukan dengan tidak memvisualisasikan wartawan yang sedang melakukan wawancara pada saat acara gosip. Selanjutnya, juga terjadi penciutan terhadap tokoh Doli, Rodiyah, Rahmah, Hafis, Syahrial, Wahyudi. Proses penambahan juga dilakukan ketika liburan sekolah. Marshila mengunjungi neneknya dan tinggal untuk sementara dengan neneknya. Alasan Mashila tinggal dengan neneknya karena masih kesal dengan bapaknya. Adapun adegan tersebut seperti terlihat pada capture film Cahaya Cinta Pesantren berikut ini:

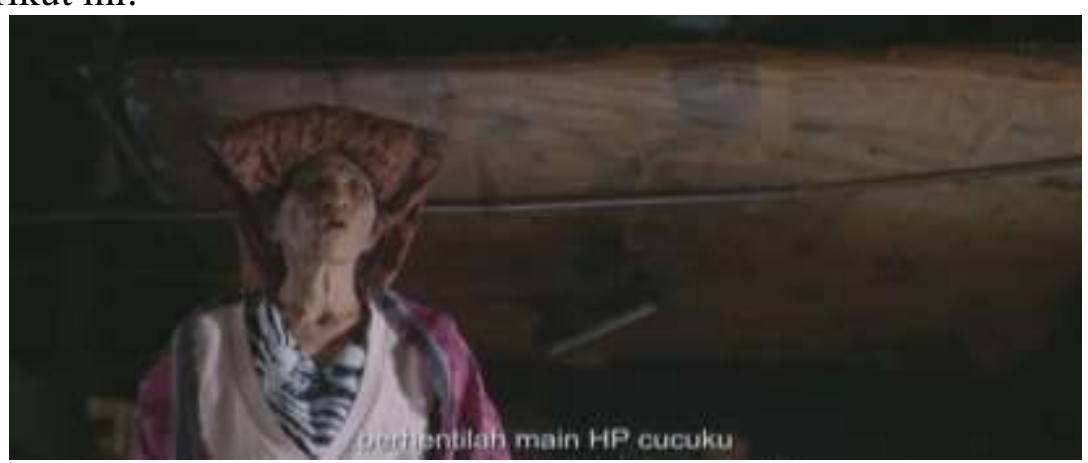

Gambar 5. Visualisasi Nenek Marshila

(sumber: Capture film Cahaya Cinta Pesantren. 2016)

\section{III.2. Tahap Konfrontasi Pada Film Cahaya Cinta Pesantren}

Tahap Konfrontasi dalam film Cahaya Cinta Pesantren kurang lebih 30 menit dari keseluruhan durasi film Cahaya Cinta Pesantren. Pada tahap ini film Cahaya Cinta Pesantren mengalami konflik yang diawali dengan kejadian salah memakai kaos kaki. Kaos kaki yang Marshila pakai berwarna putih seharusnya berwarna hitam agar sesuai dengan baju pramuka yang dipakai. Adapun adegan Marshila memakai kaos kaki hitam seperti terlihat pada capture film Cahaya Cinta Pesantren berikut :

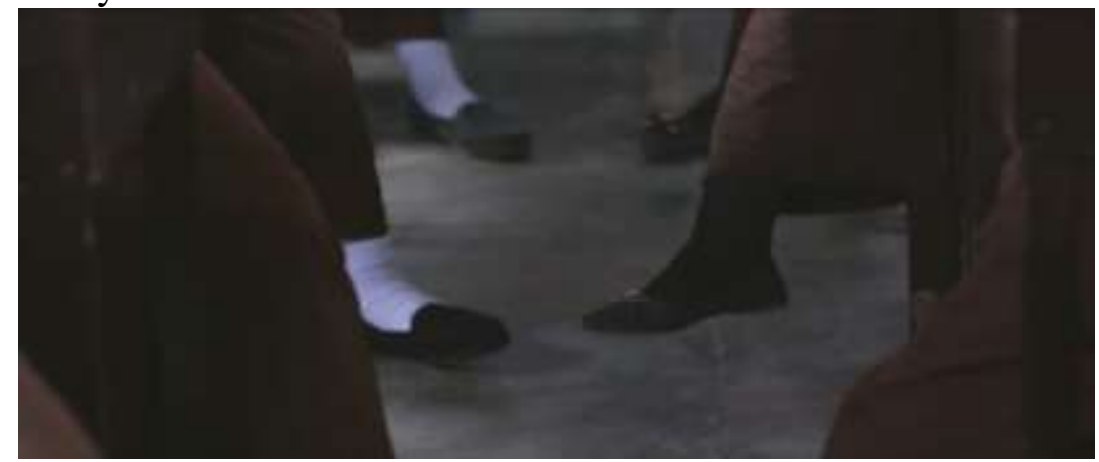

Gambar 6. Kesalahan Memakai Kaos Kaki (sumber: Capture film Cahaya Cinta Pesantren. 2016)

Ketika Marshila mendapat tugas untuk pergi meliput kegiatan perlomba silat. Rasa cemburu dan keraguan Marshila muncul ketika melihat rifqi berbicara dengan seorang cewek. Namun, semuanya terjawab kalau cewek yang baru saja berbicara dengan rifqi adalah sepupunya. Rifqi sudah dianggap seperti kakak sendiri oleh perempuan tersebut. Perempuan tersebut mengatakan walalupun hanya sepupu hubungan pariban tidak berlaku terhadap mereka. Marshila kaget ketika perempuan tersebut memberitahu hubungannya dengan rifqi. Akajn tetapi, perempuan tersebut mengatakan kalau Marshila berhak tahu akan hubungan antara Rifqi dan dirinya. Dalam tahapan konfrontasi ini juga terjadi penambahan yang terjadi didalamnya. Proses penambahan tersebut dilakukan dengan menambahkan bahwa Rifqi mempunyai seorang sepupu perempuan. Sepupu rifqi menitipkan Rifqi kepada 
Marshila ketika Marshila akan pergi meliput pertandingan Silat antar Pesantren. Adapun adegan tersebut seperti terlihat pada capture film Cahaya Cinta Pesantren berikut ini:

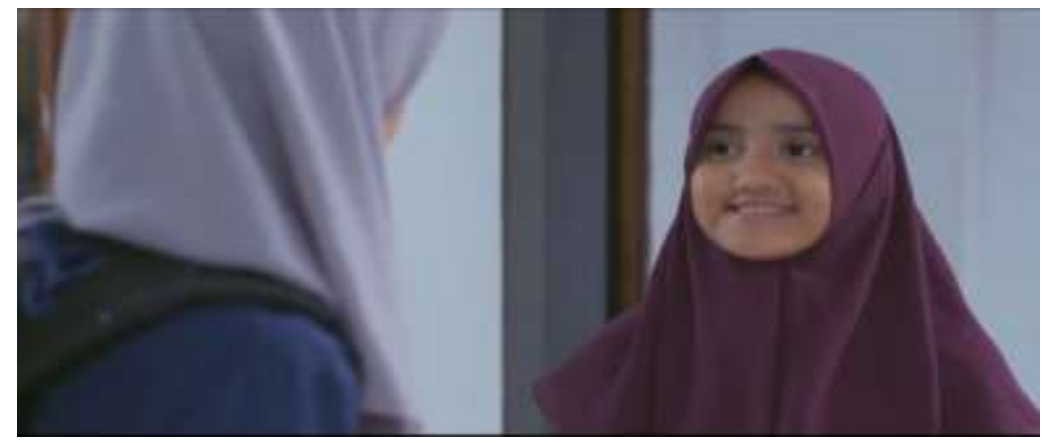

Gambar 7. Sepupu Rifqi Sedang Berbicara dengan Marshila (sumber: Capture film Cahaya Cinta Pesantren. 2016)

Dalam tahapan ini juga banya dilakukan proses penciutan maupun penambahan yang dilakukan. Hal demikian bertujuan untuk menambah alur dramatik disetiap alur cerita yang terdapat di dalam film Cahaya Cinta Peantren. Salah satu bentuk penambahan yang dilakukan ketika Marshila kaget ketika dia datang ke kantor Pesantren untuk menemui Rifqi dan di dalamnya terdapat beberapa orang ustazd. Ketika sudah sampai di dalam kantor dan bertemu dengan Rifqi dan Rifqi merasa kaget dengan kehadiran Marshila. Sehingga terjadi perdebatan antara Marshila dengan Rifqi. Adapun adegan tersebut seperti terlihat pada capture Film Harani Adat dibwah ini:

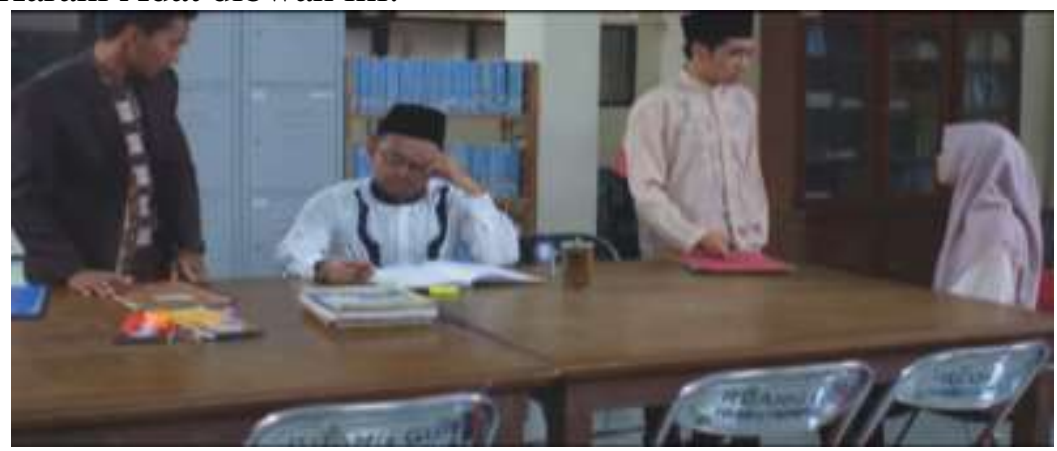

Gambar 8. Sepupu Rifqi Sedang Berbicara dengan Marshila (sumber: Capture film Cahaya Cinta Pesantren. 2016)

Dalam tahapan konfrontasi ini Marshila masuk ke dalam divisi jurnalistik. Divisi jurnalistik bertugas untuk meliput setiap rangkaian acara yang ada di dalam pondok Pesantren dan diluar Pondok. Marshila ditugaskan meliput acara pertandingan pecat silat antar pesantren. Ketika berada ditempat peliputam pencak silat. Marshila sangat kesal terhadap tingkah Abu yang selalu menggodanya. Pencat silat merupakan sebuah keunggulan yang dimiliki oleh sebuah Pondok Pesantren. Pencak silat bertujuan agar para santri mampu menjaga diri dengan menerapkan prinsip keimanan dan tidak digunakan untuk kejahatan. Ketika Marshila melihat Rifqi bertanding, Marshila sangat antusias menontonnya dan sangat berharap supaya rifqi bisa menang. Melihat gerak-gerik Marshila melihat Rifqi bertanding membuat Abu sadar diri kalau Marhila lebih memilih Rifqi dari pada dirinya. Ketika pertandingan selesai Marshila mulai mewawancarai Rifqi. Ketika Marshila mewawancari Rifqi. Rifqi menyinggung kesukaan Marshila yang hobi menulis. Marshila hobi menulis karena dengan menulis mampu membebaskan beban yang dipingkul olehnya. Rifqi mengatakan kalau dia tidak suka membaca novel karena terlalu mengikuti perasaan dan 
mengikuti perasaaan itu tidak enak. Adapun capture film Cahaya Cinta Pesantren Pertandingan pencak silat seperti terlihat pada capture berikut ini:

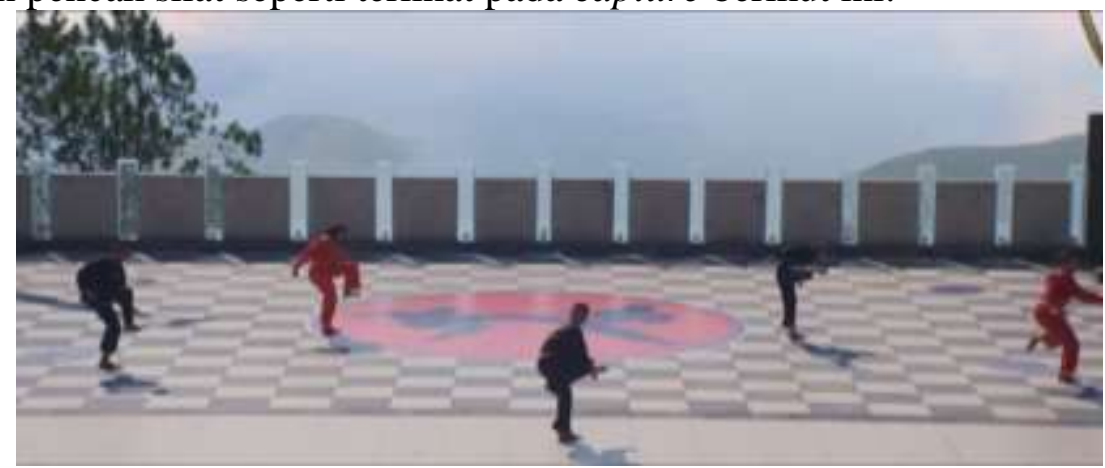

Gambar 9. Pertandingan Pencak Silat

(sumber: Capture film Cahaya Cinta Pesantren. 2016)

Di menit 1:40:49 dalam film Cahaya Cinta Pesantren Marshila mendapat telfon dari ibunya. Ibu Marshila memberi kabar bahwa bapaknya sudah meningeal dunia. Koflik bathin yang menyiksa Marshila semakin menjadi karena karus kehilangan orang yang selalu ada solusi ketika dia terkena masalah. Marshila menyadari kesalahan yang di lakukan dengan tidak memperdulikan bapaknya ketika menjeguknya ke Pesantren. Adapun adegan tersebut seperti terlihat pada capture film Cahaya Cinta Pesantren berikut ini:

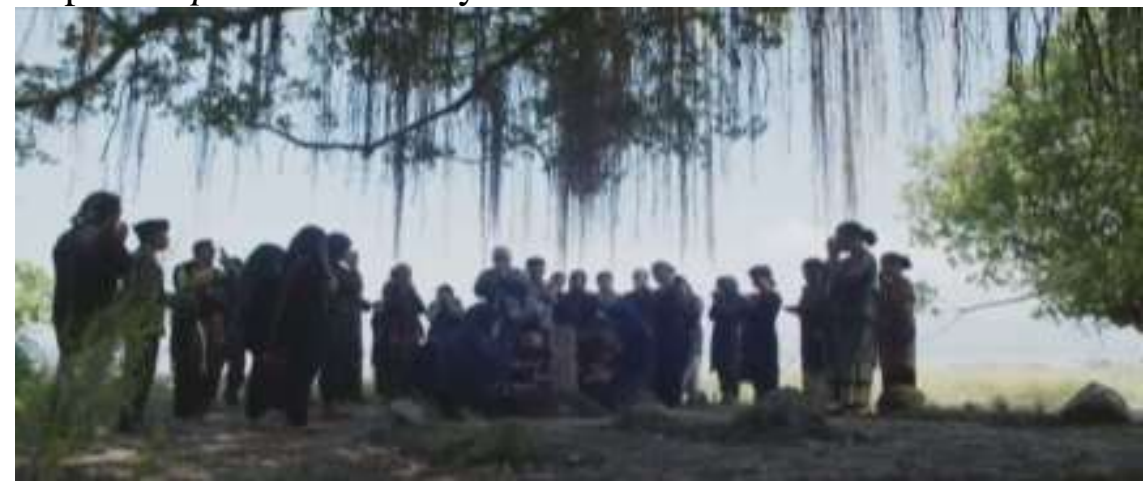

Gambar 10. Suasana Pemakan Bapak Marshila (sumber: Capture film Cahaya Cinta Pesantren. 2016)

Dalam film Cahaya Cinta Pesantren juga dilakukan proses perubahan bervariasi. Perubahan bervariasi dilakukan agar alur cerita dan tokoh penokohan dapat menimbulkan efek dramtis dalam menggiring konflik untuk mencapai puncak klimaks dalam film Cahaya Cinta Pesantren sutradara Raymond Handaya. Salah satu bentuk perubahan tersebut adalah adegan Marshila menaggis dipusara bapaknya. Dia menyadari perbuatan yang dia lakukan terhadap bapaknya dan belum meminta maaf. Marshila bergumam diatas pusara ayahnya, bahwa ayahnya adalah sosok perancang rumah yang hebat dan beridir ditengah tiang-tinag yang kokoh. Sosok bapak yang tiada pernah mengeluh akan tingkat laku Marshila dan selalu siap memberi solusi kepadanya. Rasa kesedihan semakin menyelimuti Marshila. Akan tetapi, teman-temannya di Pondok Pesantren selalu ada menjadi penghibur dirinya di kala kesedihan karena mereka memiliki belangan air mata yang berfungsi untuk menupah air mata kesedihan dan kegembiraan. adapun adegan tersebut seperti terlihat pada capture film Cahaya Cinta Pesantren berikut ini: 


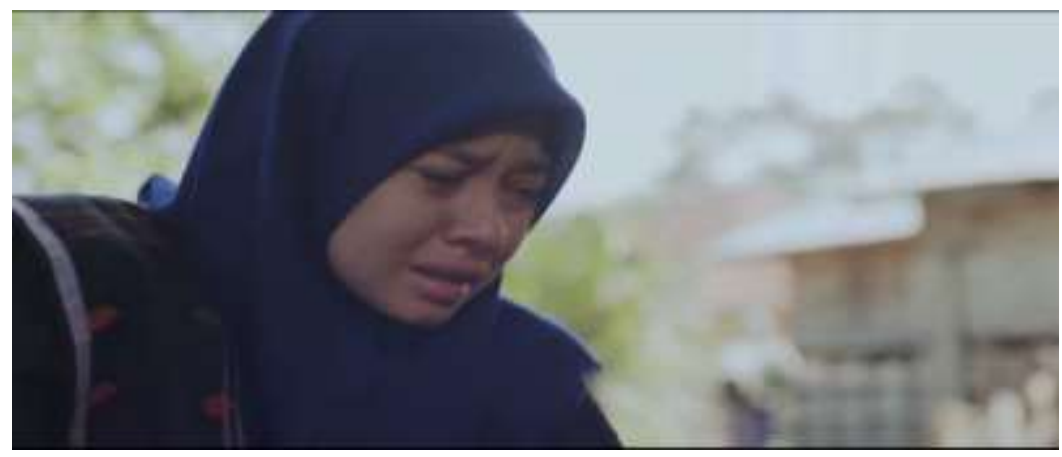

Gambar 11. Marshila Menanggis di Pusara Bapaknya (sumber: Capture film Cahaya Cinta Pesantren. 2016)

\section{III.3. Tahap Resolusi Pada Film Cahaya Cinta Pesantren}

Dalam film Cahaya Cinta Pesantren tahap resolusi berdurasi kurang lebih 30 menit. Dalam tahapan ini film Cahaya Cinta Pesantren akan mencapai titik klimaks dari setiap adegan dan alur cerita yang terdapat dalam film Cahaya Cinta Pesantren. Setelah kepergian ayahnya Marshila sangat giat belajar dan menulis. Marshila mengikuti perlombaan menulis Travel Writing. Bagi pemenang akan mendapatkan beasiswa 50 juta tunai. Kegiatan perlombaan tersebut didapat oleh Marshila dari pengumuman spanduk yang terpajang di pagar pondok Pesantren. Adapun capture spanduk perlombaan tersebut seperti terlihat pada capture film Cahaya Cinta Pesantren berikut ini:

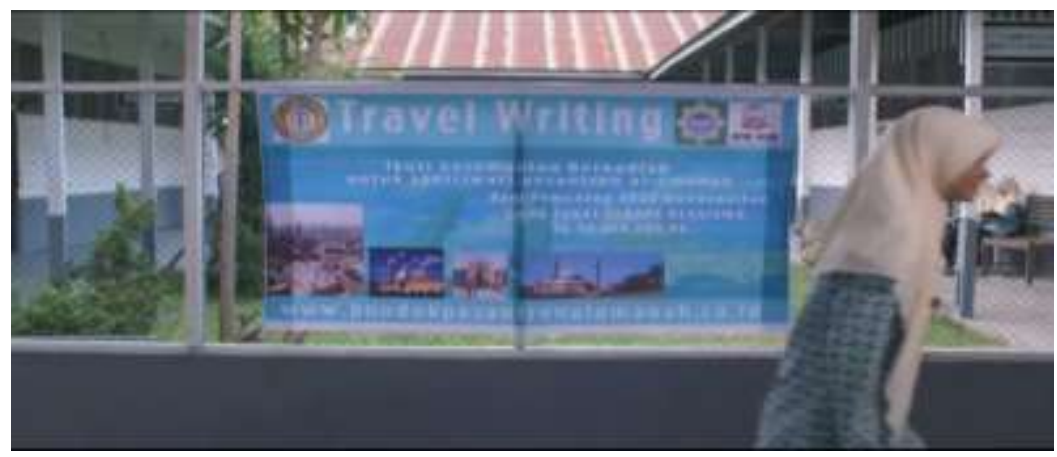

Gambar 12. Spanduk Perlombaan

(sumber: Capture film Cahaya Cinta Pesantren. 2016)

Semangat Marshila dalam mengikuti perlombaan tersebut sangat antusias. Dia menulis setiap saat agar bisa memenangkan perlombaan tersebut. Jerih payah Marshila membawakan hasil dan dia dinyatakan pemenang dari lomba tersebut. Tetapi, kegembiraan Marshila atas kemenangannya harus bercampur kesedihan. Hal tersebut disebabkan oleh Icut yang juga ikut lomba menulis tersebut tetapi tulisannya tidak sebaiki tulian Marshila. Icut menuduh Marshila berkhianat. Icut juga menilai kalau Marshila adalah orang yang egois dan dia ingin menunjukkan kalau dia adalah yang terbaik. Icut mengatakan sahabat tidak perlu berbicara akan keluh kesahnya. Seorang sahabat akn paham dengan sendirinya dengan sahabatnya yang lain. Icut sangat marah dan mengatakan belanga air mata itu hanya omong kosong. Waktu terus berlalu sehingga tibalah saatnya ujian akhir semester dan Marshila dinyatakan sebagai lulusan terbaik. Marshila diberikan kesempatan untuk memberikan kata sambutan dihadapan para santri dan orang tua yang hadir. Ibu dan kakak Marshila sangat bangga atas prestasi yang diraih 
oleh Marshila. Adapun adegan Marshila memberikan kata sambutan seperti terlihat pada capture film Cahaya Cinta Pesantren berikut ini:

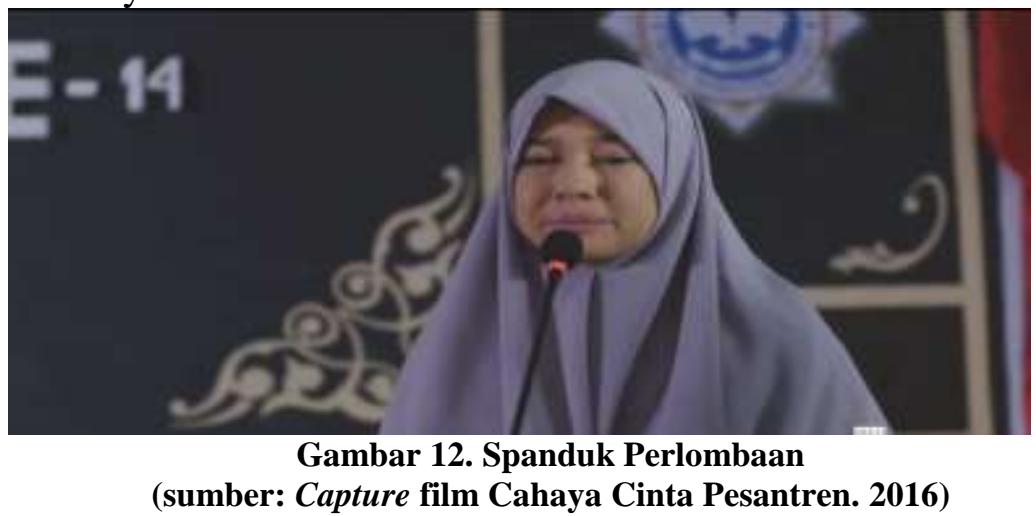

Dalam tahapan ini sangat banyak terjadi proses ekranisasi. Baik dari segi penciutan, penambahan maupun perubahan bervariasi. Dalam tahapan resolusi ini banyak alur cerita dalam novel tidak diceritakan ke dalam film seperti cerita pergi ke jepang, Marshila Masuk rumah sakit, menikah, melahirkan dan sebagainya. Proses penambahan dan perubahan bervairasi pun semakin dimasukkan ke dalam tahap resolusi ini yang bertujuan untuk mengakhiri alur cerita yang terdapat dalam film Cahaya Cinta Pesantren agar bisa mencapai klimaks. Marshila mengatakan jika kita mencintai sesuatu karena asma Allah makan kita tidak akan mengenal yang namanya sakit hati. Dalam film Cahaya Cinta Pesantren dapat diambil pelajaran bahwa setiap masalah yang menimpa tentu memiliki solusi dalam menyelesaikannya dan jika keinginan tidak terpenuhi dengan baik mungkin itu bukan yang terbaik untuk kita.

\section{KESIMPULAN}

Dalam film Cahaya Cinta Pesantren terdapat proses penciutan baik dari segi alur cerita maupun tokoh dan penokohan. Dalam film Cahaya Cinta Pesantren juga dilakukan proses penambahan yang bertujuan agar alur cerita dalam film Cahaya Cinta Pesantren memiliki kesinambungan satu dengan yang lainnya. Proses perubahan bervariasi dilakukan bertujuan untuk menambah efek dramatis agar mampu menggiring konflik cerita dengan baik dan bisa membuat penonton tersentuh dan masuk ke ranah cerita film pada saat menontotnya. Belanga air mata yang dimiliki Marshila dan teman-temannya menunjukkan betapa pentingnya sebuah wadah yang berfungsi sebagai penampung kesedihan maupun kebahagian. Belanga air mata tersebut tercermin dari persahabatan yang terjalian diantara mereka selama berinteraksi di pondok Pesantren. Film Cahaya Cinta Pesantren juga mencerminkan pentingnya tekad yang kuat ketika menginginkan sesuatu.

\section{DAFTAR PUSAKA}

[1] Andini, Bertha Galuh. 2016. "Ekranisasi Unsur Naratif Dalam Film Life Of Pi”. Dalam Jurnal Capture, Vol. 7 No. 2. Institut Seni Indonesia Surakarta.

[2] Bluestone, George. 1957. Novels Into Film. London: University of California Press. 
[3] Emalya, Selly. 2017. "Analisis Naratif Ekranisasi Novel "Supernova: Ksatria, Putri Dan Bintang Jatuh” ke Dalam Bentuk Film”. Skripsi. Program Studi Televisi dan Film. Institut Seni Indonesia Yogyakarta.

[4] Garin, Nugroho. 1995, Kekuasaan dan Hiburan. Yogyakarta: Bentang.

[5] Nurgiyantoro, Burhan. 2010. Teori Pengkajian Fiksi. Yogyakarta: Gadjah Mada University Press. 